\title{
Discussion on the Effect of Machining Process Technology on the Machining Accuracy
}

\author{
Fang Chen \\ Xi'an Aeronautical Polytechnic Institute; Xi'an 710089 China
}

Keywords: Machining; technology; machining accuracy; effect.

\begin{abstract}
The part qualification rate of enterprises will be affected by various factors when the machine parts are processed, which will cause some effects on the whole project in the process of producing machine parts. Machine parts process can directly influence their accuracy in the machining process technology. And accuracy is a vital index of machine parts, which means comparing the real size and shape with the part accuracy in the ideal layer. The higher relevance means the higher part accuracy, which can make better machining technology. While any problem will affect the accuracy of technology system in the specific practical process, so the deviation should be attempted to avoid.
\end{abstract}

\section{Introduction}

Machining process technology represents the production and manufacturing level of industry, and the machining process has been more complex in the current society with increasingly developing machining process technology. In the process, the accuracy will be affected if the machining process technology cannot get rational and effective control, and then it will affect the rational application of machining process technology, so the machining productivity cannot be formed. In the real work, the application layer of affecting machining process technology should be firstly discussed to explicitly know the factors that affect the machining process technology and practically improve its level. This paper will discuss the effect of machining process technology on the machining accuracy.

\section{Discussion of Machining Process Technology on the Machining Accuracy}

There will exist many objective factors that limit and affect the machining operation. It is of great necessity to make the rational discussion with the machining process technology of communication technology in order to make the fast and accurate transmission bring some effects on the machining and influence the rapid development of communication. Machining accuracy is vital for the machining process technology. The reasons are that machining accuracy can achieve the fast exchange and transmission of information, accurately and effectively master the usage with machining part, improve the working efficiency and the whole quality of machining parts. The higher accuracy means the lower reworking rate.

\section{Internal Factors of Machining Process Technology on the Machining Accuracy}

1. Internal factors and reasons of machining accuracy. The geometric accuracy of machining process technology is the internal factor of influencing the machining accuracy when the machine parts are processed. Because machining is controlling the machine parts, the accuracy of machining process technology is mutually influenced and restricted with machine tool. The zero deviation of machine tool accuracy can make that machine parts are ensured in the machining process. For instance, the spindle of the machine tool has some problem in the radial swing, which may cause the deviation of rotation and affect the accuracy of machine parts. If there are a series of problems and mistakes in the machine tool installation, the accuracy of machine parts will be directly influenced.

There will always exist the condition of being frayed in the long-term work and operation of machine tool, which will also affect the machining accuracy. Especially, the fray is more likely to appear under the circumstance of the cutter being used for too long time and too many times. If the 
cutter has some deviations in the producing process, then the machine too can be changed and adjusted to some degree in the practical application and to reduce the machining inaccuracy and even guarantee the accuracy of machining parts. However, in the process of usage, the cutter will be frayed, and the corresponding place on the machine tool of the cutter will ultimately have an heavy effect on the quality and accuracy of machining parts. In the whole machining process technology system, the fixture is the best tool to keep the distance from the cutter to the part. Only by ensuring the cutter accuracy can the accuracy degree of machining parts be guaranteed. But the cutter is more likely to appear the following error in its usage that the improper operation will affect the machining and installation of parts even fray the parts in a long time.

2. The countermeasures to internal factors of machining accuracy. The problems existing in the original period of mechanical equipment and errors happened by the friction in the usage should be scientifically and effectively solved. In the real machining process, the existing errors in processing parts are supposed to be effectively controlled by the modern technological methods to ensure the part deviation in the controllable range. Normally, the machine tool with high accuracy will set the components that can reduce and control the errors. And they can timely control and rectify the errors appearing in the machining process to ensure the accuracy of every part and procedure. For the ordinary machine tool, if there is the breakage or friction in the machining process, the setting methods of rectifying the scale data value and operating by hand can be adopted to compensate the errors in the part processing.

\section{External Factors of Machining Process Technology on the Machining Accuracy}

1. Thermal deformation in the operation of machining process technology. It will affected by many external factors which mainly mean the influence of natural condition like the weather. And different thermal effects will make the parts appear the deformation and the damage between the cutter with part become stronger. As a result, the accuracy of machine parts will be affected, and the error will certainly exist. It will reach about 50 percent in severe conditions, especially for the part with higher accuracy, the error will be bigger. The writer will analyze the thermal deformation part in the machining process.

The first one is that the processed parts appear the thermal deformation. Parts are in the complete condition before the machining, but the machining process has a higher requirement with the accuracy. So lots of heat will affect the surface of parts and then result in the error of temperatures on the two surfaces. Due to the thermal error, parts will appear the deformation, and the error will still appear even if the surplus part in the machining process have been handled. Therefore, staffs can add the cutting fluid on the parts and cutter to reduce their temperature. In addition, the clamping strength should be increased in the process of clamping machine parts so as to compensate the appearing errors or adjust the cutting parameter to decrease the friction and lower the heat.

Next one is that the cutters of machining process technology appear the thermal deformation. The reason is that a series of heat will appear in the cutting process. In the beginning of cutting, there will form some heat because that constant cutting of cutter parts. While this heat is the main reason of cutter deformation. In order to reduce the effect of deformation on the machining parts accuracy, the cutting parameter should be mastered on the basis of appropriate cutter selection and reduced in a short time.

The last one is that the machine tool will produce some heat in the movement, and all the parts will have an effect on each other because of the friction. The heat will be higher and higher along with the sports time extension of machine parts. So the temperature of machine tool will gradually go up. And the place of parts will heavily change, having an bad effect on the machining accuracy. In the machine tool, all the parts will lead to the upward temperature on the surface of machine tool due to the friction. So in order to effectively solve the machining accuracy in the practical operation, the heat around the machine tool can be reduced and some lubricant can be used to reduce the friction of machining parts and some refrigeration equipment can be added to reduce the temperature.

2. Pressure deformation in the machining process technology. Due to the rather complex procedures and bigger strength and pressure of multiple sites, machining parts are in the moving 
condition for a long time. So machine is easy to deform in the accelerating movement. For instance: the tiny components such as the cutter should make the corresponding adjustment and change in the machining process. Along with the shape change produced by the long-term machining process technology, the corresponding places of these parts will also change and result in the change of their own work track. Finally, it will lead to the deformation of parts. As the following figure:

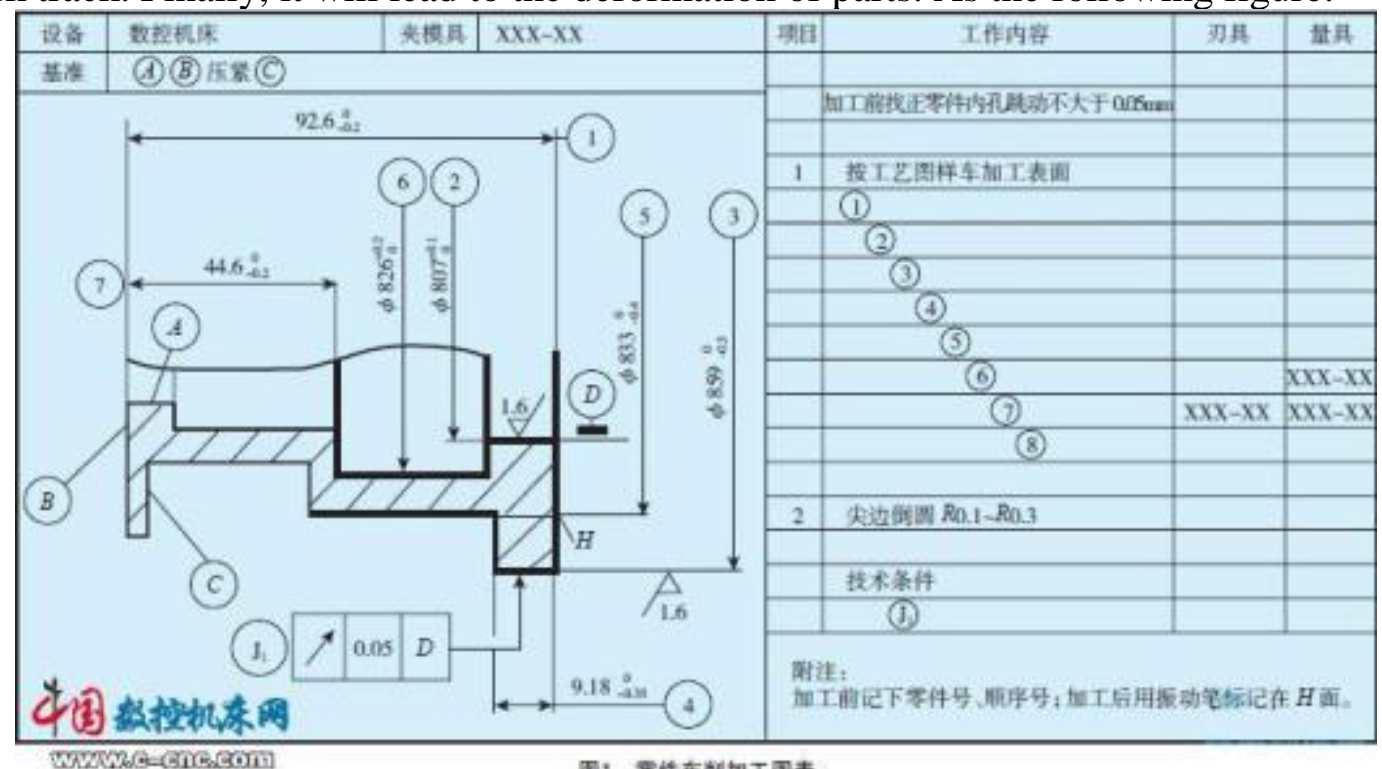

Fig. 1 it will lead to the deformation of parts

Too much pressure will reduce the machining accuracy, so the stress condition of machining system can be adjusted through the accuracy adjustment. Firstly, the machining system parts can be adjusted in the operation to strengthen the rigidity of machining process and the anti-pressure ability of the whole system so as to prevent the deformation of machining process system in the long-term movement. In addition, there will exist lots of heat in the operation, which also is a significant factor of deformation. For example, machine parts will have some effect on processing system after the heat treatment, leading to the shape change under the condition of without external force of the whole system. However, in the practical work and operation process, the heat should be reduced when the machining parts stop the procedure to decrease the thermal adaptation. What's more, the machining process of parts should be rationally arranged to avoid other pressure, reduce the accuracy error and strengthen the anti-pressure of parts.

\section{The Countermeasures of Applying Machining Process Technology to Strengthen the Machining Accuracy}

1. Technical essentials to optimize the machining process technology. The practical operation of machining process should make the comprehensive and systematic analysis with the errors existing in the machining parts and control the existing errors in the work to strengthen the machining accuracy. In addition, the specific machining process should connect the own characteristic of machine tool and compensate the missing accuracy in the machining process with the distinct method. Along with the appearance of electronic science and technology, the digital machine tool can be used in the operation process to rectify the specific software and the damage of various technology systems. As for the operation of ordinary machine tool, it can only handle the machine by hand not the electronic technology and science. However, it is still easy to appear the error after the control by hand. After the machine stopping work, the related staffs should regularly check and try out the machining equipment and maintain the appliance with problem to guarantee the equipment in the best working state. Such method can not only improve the working efficiency, but also effectively promote the machining accuracy.

2. Optimize the machining accuracy. The improvement of machining accuracy is the essential working requirement of the whole machining process. In the machining process, the machining level 
should be scientifically and effectively improved to strengthen the operation technology and equipment quality. In addition, it should connect the Internet to innovate and change machining process technology based on the scientific concept in the new era and introduce new machining process equipment through modern machining process technology. What's more, all the staff of machining process should strengthen their own operation ability and level in their spare time, improve the study with machining theory knowledge and connect the theory knowledge with practical operation and apply it to the machining process so as to achieve the machining effect and comprehensively improve machining process technology and guarantee the machining accuracy.

3. Introduce the digital machine tool of machining process technology. Along with the progress of era and constant development of science and technology, the selection with machine tool also needs to base on the direction of era development and the machining efficiency should be improved on the basis of quality to achieve the two purposes. Traditional ordinary machine tools have been abandoned by the era. Nowadays, the main machining tool is digital machine tool that is the product under the background of information era. Therefore, the intelligent application should be adopted to effectively improve the machining accuracy. Intelligent operation is the product of new era and it restructures the intelligent error compensation control and optimization control of complex machining movement track through the method of integrating various information. On the basis of using the modern information technology, the machining process technology such as the flexible producing system can be used to improve the production effect and satisfy various allocation to achieve the machining effective production.

\section{Conclusion}

In summary, this paper comprehensively discussed the effect of machining process technology on the machining accuracy from the four aspects. Along with the constant reform of national economy reform and progress and development in the field of science and technology, machining also has been improved to some extent. The writer thinks that the machining accuracy should be made the further research in the machining process. In addition, the new management model and concept of the new era should be integrated to introduce new information control technology, constantly strengthen the level of machining process technology and enhance the machining accuracy. At the same time of improving the efficiency of machining work, the qualification rate of products should be effectively promoted to make the machining process technology have the advantage in the fierce market competition and promote enterprises achieving the strategic development target.

\section{References}

[1]. Yongqing Xia. Thought on the Effect and Control of Machining Process Technology on the Machining Accuracy[J]. Science \& Technology Industry Parks, 2017(23):129.

[2]. Kaisong Lei. Study on the Effect of Machining Process Technology on the Machining Accuracy of Parts[J]. Chinese Strategic Emerging Industries, 2017(20):165+167.

[3]. Lin Li, Peng Guo. Discussion on the Effect and Control of Machining Process Technology on the Machining Accuracy of Parts[J]. Engineering and Technological Research, 2017(01):96+98.

[4]. Wansheng Gao. Study on the Countermeasures of the Effect of Machining Process Technology on the Machining Accuracy of Parts[J]. Horizon of Science and Technology, 2015(12):85+200.

[5]. Guowei Yuan. Analysis of the Technical Measures of Improving the Machining Accuracy of Parts[J]. Science \& Technology Association Forum (The Edition of Latter Month), 2013(05):5859.

[6]. Wenchao li. Study on the Effect of Machining Process Technology on the Machining Accuracy of Parts[J]. Modern Salt Chemical Industry, 2017,44(02):17-18. 